\section{UK rejects call for more systematic biology cash}

London. Despite claiming a growing awareness of the need to preserve global biodiversity, the British government has rejected demands from the House of Lords that it should provide extra funding for research in systematic biology, the basic discipline which underpins such efforts.

Eighteen months ago, the science and technology committee of the House of Lords issued signals with a strongly worded report warning that systematic biology — the classification of living organisms based on their evolutionary relationships - was in a state of crisis (see Nature 355, 488; 1992).

The committee pointed out that there had been no increase in funding during the 1980 s, that research council funding had fallen by a third over this period, and that research staff in the museums responsible for maintaining national collections of biological materials had dropped by 25 per cent.

In its response to the report, published last week, the government's Office of Science and Technology (OST) says it endorses the importance of systematic biology as a discipline underpinning its policy initiatives on biodiversity and the environment, and accepts several of the committee's conclusions.

For example, OST has promised to carry out a review of microbial culture collection in Britain to see how these meet national needs, and how a strategy for the future might be developed. It would like to see increased funding for systematics research in the next Framework programme of the Commission of the European Communities.

The government has also agreed to fund a national forum bringing together the main public and private institutions working in the field. The purpose, it says, will be to disseminate information and "good practice" among the bodies which maintain sizeable systematics collections, and to strengthen links with overseas institutions in order to build up an international framework for the subject.

But there will not be any more money or even any firm commitments to maintain funding at current levels. The Lords committee had proposed that the research councils be given an extra $£ 1$ million a year over the next five years to make good the previous decline. However the OST says it agrees with the Advisory Board for the Research Councils that there is no case for giving systematic biology any special treatment.

Similarly, the government rejects the committee's suggestion that core funding for both systematic biology research and the national institutions where much of it is carried out be maintained at current levels. It says that earmarking resources in such a way "would not allow museums the freedom to target areas which, in their assessment, warrant priority action."

The lack of any new funding has come as a disappointment to the scientific community. "Even with current funding difficulties, people had been hoping for something a little more positive than this," says Michael Claridge, professor of entomology at the University of Wales College of Cardiff, who acted as an adviser to the Lords committee. "The government's reaction is bound to have a deadening effect."

The reaction of museums, already facing the possibility of further cuts in their operating budgets, has been similar. Neil Chalmers, the director of the Natural History Museum - which, as one of Europe's main centres of systematic biology, is already offering to host the national forum which the government has promised points out that the museum is finding it

increasingly difficult to maintain core funding for systematic research at a time when its government grant is being reduced.

Government officials point out that the House of Lords report has already helped to focus the attention of the scientific community on the difficulties facing systematic biology. For example, the Natural Environment Research Council (NERC) recently awarded new grants totalling $£ 2.5$ million over five years to support taxonomic research and training relevant to the environmental sciences at three British universities (see Nature 362, 383; 1993).

But there is widespread feeling that the efforts remain inadequate to the need. The NERC money, for example, will be able to support only short-term appointments, whereas the main need faced by universities is how to fill the senior academic posts that will become vacant over the next few years when their current occupants retire.

Similarly, while the government continues to claim credit for having allocated $£ 6$ million over the next few years to back up its commitment to biodiversity, Lord Dainton, the chairman of the House of Lords Committee, describes this as "a complete mouse" compared to the needs.

David Dickson

\title{
Hillary Clinton lobbies at Hopkins for health
}

Baltimore. Hillary Rodham Clinton, whose husband, US President Bill Clinton, made her head of his task force on health care reform, took her message to US academic researchers for the first time last week, at the centennial celebration of the Johns Hopkins University School of Medicine. Addressing an audience of research physicians, academic scientists and staff at one of the elite medical institutions of the United States, Mrs Clinton declared that what the country needs most is a larger corps of general "primary care" doctors to work in small towns and inner cities, attending to routine medical needs.

The debate on primary care versus specialism is at least a decade old. Mrs Clinton said last week that if medical schools did not change the curriculum to induce more students into primary care, the government would force the issue, perhaps by offering "forgiveness" of educational loans to doctors choosing general medical practice.

Mrs Clinton also suggested that the health reform package would include a proposal to alter or eliminate the capitation funds that medical schools receive by law from the federally run Medicare system. As things are, the government recognizes an obligation to reimburse hospitals for the care provided by medical residents in training at US teaching hospitals. Cutting the Medicare allowance would save the government an estimated $\$ 12$ billion a year - or put teaching hospitals in debt by the same amount.

While praising Hopkins for its accomplishments in research and successful high-technology medicine, Mrs Clinton warned academic hospitals that they must find ways of extending their expertise more broadly into the community. She said, for example, that more attention should be paid to information networks that would enable a small town physician to send a CAT scan electronically to an academic centre where a specialist could read it on a monitor.

Mrs Clinton also paid lip service to funding for basic biomedical research when she said, "We will look for ways to support it" (perhaps not intending to imply ignorance of the US National Institutes of Health), but then closed with an admonition to doctors of all stripes to spend more time talking to their patients about diet, nutrition and exercise, while also "cooperating" more effectively with nurses and each other.

Despite its modest content, Mrs Clinton's speech was well received and won praise for the professionalism of her delivery. The Clintons' health care task force has been notable for the groups that have been deliberately left out of the planning on the grounds that they constitute a special interest and are, therefore, unable to offer objective advice.

That the White House accepted Hopkins' invitation to Mrs Clinton may, in the circumstances, be taken as a sign that the research community has been recognized as an important constituency in the debate on the reform of health care. Despite the president's best intentions, that is unlikely to end soon.

Barbara. J. Culliton 